\title{
The Nesin Mathematics Village in Turkey
}

\section{Krishnaswami Alladi and Gabriela Asli Rino Nesin}

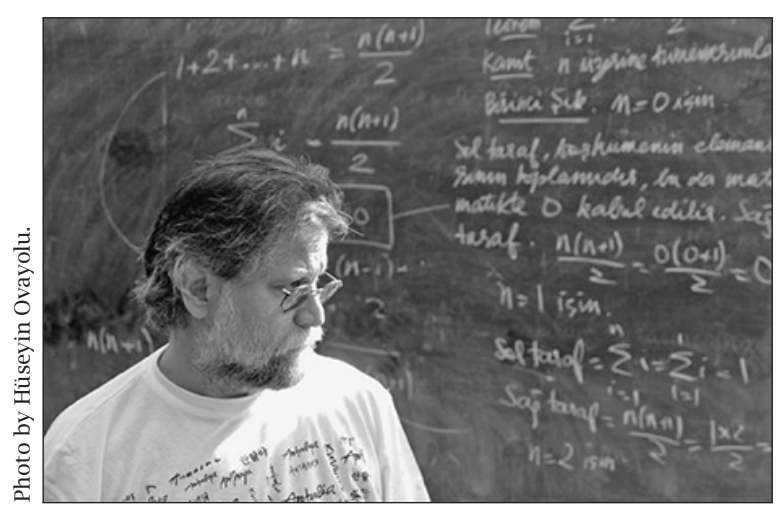

Ali Nesin with surprisingly tame hair.

\section{PREFACE:}

\section{Krishnaswami Alladi}

In August 2014, my wife, Mathura, and I were on a three-week visit to Turkey. I participated in a conference on algebra and number theory in Samsun on the Black Sea coast in northern Turkey, and after that we went on a one-week sightseeing tour of Turkey. Professor Ali Bülent Ekin of the University of Ankara, who was one of the organizers of the conference and my host in Turkey, graciously offered to take us on a 1,500-mile journey to see several ancient historical sites of the Greek, Roman, and Ottoman periods. One of the places we visited was Selçuk, a town which is close to the city of İzmir and known for the well-preserved ruins of Ephesus, as well as the not-so-well-preserved ruins of the Temple of Artemis, one of the Seven Wonders of the Ancient World. After a long, enjoyable, but tiring day of

Krishnaswami Alladi is professor of mathematics at the University of Florida. His email address is a11adik@uf1 . edu.

Gabriela Asli Rino Nesin is a graduate student in computer science at the University of Leicester. Her email address is garn1@1e.ac.uk.

DOI: http://dx.doi.org/10.1090/noti1258 sightseeing, Ali Bülent suggested at dinner that we should see the Mathematics Village on the outskirts of Selçuk that very night. It was late, and so I felt that the Mathematics Village might be closed. But Ali Bülent said that it was only 9 p.m., and the night was young. So we departed for the Mathematics Village right away without any appointment to see anyone.

The Mathematics Village is nestled in a mountainous region in the village of Şirince, and it was quite scary as Ali Bülent navigated the narrow unpaved roads to reach the Village. It was pitch dark as we parked, but in the glare of our headlights we suddenly saw a female student emerge from a path, proceed to her tent, pick up a notebook, and head back along the path from which she came. So we knew we were at the right place and followed that path. A lovely set of buildings loomed very soon, and we were greeted by a cheerful band of students. We were taken immediately to the terrace where Prof. Ali Nesin, the founder of this wonderful institution, and his daughter, Gabriela, were in discussion with students at dinner. They spontaneously invited us to join them at dinner, but we had to decline the kind invitation since we had already dined in Selçuk. Gabriela then showed us around this remarkable place. We were simply overwhelmed by what we saw.

The Mathematics Village is a unique institution. It offers short but intense courses to mathematics students from high school and college. The students are immersed in mathematics for the few weeks they are there, learning from the professors who teach, as well as from discussions among themselves. The students could relax in the evenings by playing Ping-Pong or cards or by simply reading in the excellent library or in the wooded environs. Most students are housed in stone and clay houses, but as demand almost always surpasses capacity, some have to be put up in tents. At the time we visited, there were about four hundred students in attendance. Teaching is voluntary; while the Mathematics Village does not 
provide honoria for the teachers, it provides free accommodations and meals. It is a sylvan setting in which to either learn or teach mathematics. As we toured the Village, I was impressed to see some students in discussion in front of a blackboard in a courtyard and some others in the library, even in the late hours. So in the midst of the sightseeing tour, we had a wonderful opportunity to visit this remarkable institution.

Gabriela, who occasionally volunteers at the Village as well, has described the conception and evolution of this rather unique educational enterprise.

\section{THE MATHEMATICS VILLAGE: PAST, PRESENT, AND FUTURE}

Gabriela Asli Rino Nesin

The most popular T-shirt for sale at the Nesin Mathematics Village these days depicts a distracted mathematician who, after having completely filled his blackboard with a gigantic equation, simply keeps going on the wall next to it. The caption under it reads "Mathematicians without borders...." It is quite fitting (pardon the pun), both to the steady expansion of the Mathematics Village over the past seven years and to the voluntary nature of the Village; hence the parallel to the famous Médecins Sans Frontières.

The Nesin Mathematics Village is a small nongovernmental organization that has "colonized" a hillside near İzmir, Turkey, and has dedicated itself exclusively to the nonprofit teaching and practice of mathematics. Based on the academia of ancient Greece, it is a place where mathematics is done at every hour, in any place, and in any position, horizontal or vertical. In the next few pages I will attempt to give a taste of what the Mathematics Village does. But first, I will start by describing how the idea originated and how it graduated from idea to reality. I will then describe the various programs taking place there each summer and the various facilities available both to aspiring and card-holding mathematicians. Finally, I will show how one can take part in this enterprising project.

\section{Origins}

\section{Aziz Nesin and the Nesin Foundation}

The wild-haired, bearded, and bespectacled mathematician on the T-shirt bears a strong resemblance to the man who founded the Village, Ali Nesin. Although he has become a somewhat well-known figure in Turkey, he owes part of that fame to his father, Aziz Nesin. Aziz was one of the most famous and prolific writers in Turkey and at the same time an important leftist figure, penning many works of political satire. This and the fact that he was most likely the first publicly self-declared atheist

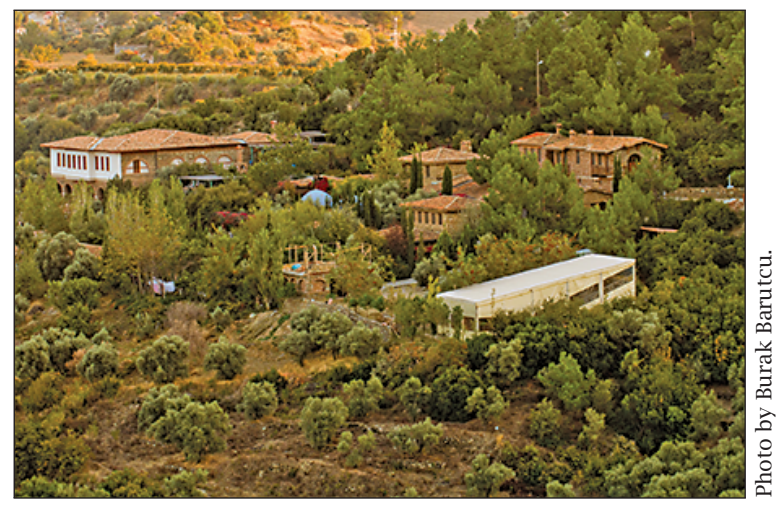

The Village from afar. The two blue domes (one of which is almost hidden) are the female and male Turkish baths. The large white building on the right is the library.

in Turkey, made him beloved to some and a sworn enemy to others.

In the seventies the income from his books allowed him to open the Nesin Foundation,a nonprofit organization taking in children from disadvantaged families and giving them a home as well as sending them to school until they completed their education (including university studies). What, one might ask, does this have to do with mathematics? Essentially, the Mathematics Village's land and assets are owned by the Nesin Foundation, and their destinies are as such very closely tied. Furthermore, the basic principles governing both are essentially the same: access to knowledge, education, and freedom.

But now let us describe how the need for a Mathematics Village became apparent, starting twelve years before it opened.

\section{Bilgi University and Its Mathematics Summer Schools}

At Aziz Nesin's death in 1995, Ali left his post as associate professor at the University of California at Irvine in order to take over direction of the Nesin Foundation in Istanbul. As luck would have it, in 1996 a private university named Istanbul Bilgi University was preparing to open its doors and hired Ali as head of the Department of Mathematics. He quickly gathered a small but tightly knit group of Turkish and foreign academics which gradually gained the reputation of providing one of the best mathematics educational programs in Turkey. The department was extremely ambitious: the students were taught axiomatic set theory the first year, including ordinals, cardinals, the Axiom of Choice, Zorn's Lemma, and even nonstandard numbers.

The advantage of a small department was that staff were able to follow students almost individually. In a class of four, one absentee meant 


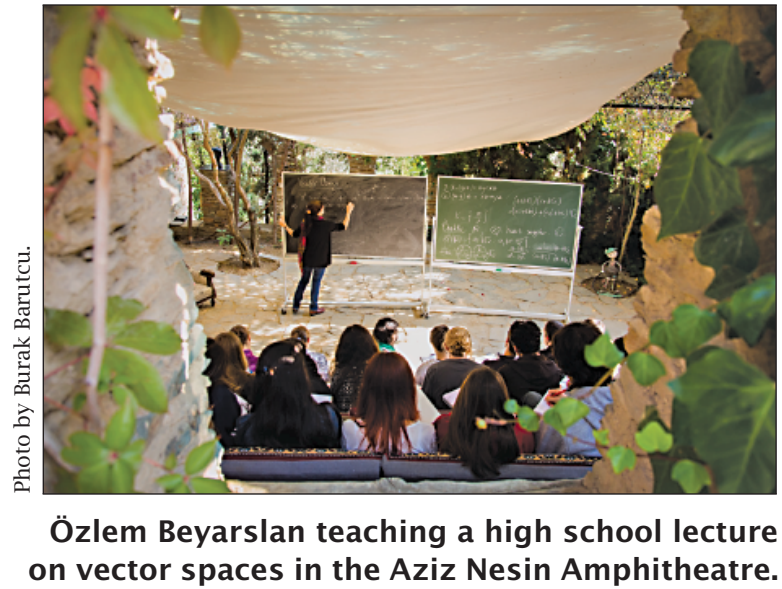

25 percent of the class was missing; it wasn't uncommon to get a phone call when one had overslept. However, it soon became apparent that more time was needed to rectify the holes left by Turkey's test-oriented high school education than was accounted for in the curriculum.

From 1998 onward summer schools of a month and a half were therefore organized in various vacation spots in Turkey, where students would study during the day and swim and bond in the remaining time. However, these summer schools (although partially funded by Bilgi University) became more and more expensive. There were other logistical problems: they once had to improvise whiteboards by sticking paper behind window panes, and it is virtually impossible to prove theorems with Enrique Iglesias blaring in the background. Ali began to think that the only way to get something done right was to do it himself.

Meanwhile, an old friend of Ali's, Sevan Nişanyan, was building a picturesque hotel in a small village near Selçuk, İzmir, called Şirince.

\section{How the Village Was Built}

In 2007 Ali Nesin bought a 2.5-acre plot of land one kilometer from Şirince and started construction on it according to the plans drawn up by Sevan and him (quite modest to begin with, although they have mushroomed over time). Sevan Nişanyan was instrumental in making the Village the place it is today; his architectural knowledge, good taste, and boundless energy have been invaluable.

That first summer of 2007 around one hundred students, mostly from Bilgi University, attended the summer school at various times. Most slept in tents. Besides attending the usual six to eight hours of lectures, students and lecturers cooked and cleaned for the whole group, planted trees, and helped the construction workers carry materials and build walls.
The structures were, and still are, built out of stone slabs, straw and clay. The first lecture hall, the Robert Langlands Lecture Hall, was built around an old tree which still juts out of its roof like a sentinel. Huge wooden beams from old train tracks were used to build the steps of the Aziz Nesin Amphitheatre, and the climbing vines which today provide its much-needed fresh green shade were planted.

\section{Legal Issues}

The area in and around Şirince is designated a protected area, making authorization for construction very difficult to obtain, since it is firmly under the control of local authorities. Although the Mathematics Village is outside the protected area, authorization for construction was never granted owing to antipathy toward the Nesin name. One of the objections raised was that it was illegal to establish an educational facility without permission from the government, even though the Mathematics Village is a nonprofit organization, does not conduct exams, or offer degrees or diplomas.

The struggles are far from over. Despite all this, the Village believes that as community support and international recognition grow, these persecutions will disappear. Furthermore, a strong communal feeling is born in trying to overcome such obstacles together.

\section{The Mathematics Village Today Summer School Social Structure}

By 2009 facilities had expanded so much that many more students from other universities could be accepted, and Bilgi students ceased being a majority. As the summer schools gained momentum, postgraduate students also started attending them. They volunteered to teach, attended classes they were interested in, and had opportunities to chat to and collaborate with colleagues and professors from around the world-an ideal and relaxed academic environment.

A standard fee to attend the Mathematics Village was decided upon, but it quickly became apparent that many university students could not afford this, as they were often no longer supported by their parents. The Village accepted the students anyway, paying for their accommodations and food costs out of its own pocket and naturally finishing each summer with a significant deficit. Even the support of the Turkish Mathematical Society and the generous donations from the Turkish population (many of them from families that could barely afford such donations) could not compensate for the losses. Due to high demand and as a way to partially counteract the deficit, the Mathematics Village decided to expand its 
audience to high school students, starting from the age of fourteen.

The high school summer schools have since become a huge hit, with the number of applications more than triple actual capacity. Although some grants are provided for disadvantaged students, the families of most high school students are more than able and happy to pay the modest fee of US\$500 for two weeks. It has become a badge of honor for a family to have sent a child to the Mathematics Village. As a result, the Village now carefully makes sure that the student really wants to attend and is not caving in to the pressure of his or her family. On the other hand, there have been a couple of cases of kids running away from home to the Mathematics Village when their parents refused to let them come to "the atheist camp"! Whatever surplus the Village obtains from high school fees is channelled toward grants for undergraduate and postgraduate students lacking the means to attend.

During their two-week stay, all high school students will be under the responsibility of a "big brother or sister," akin to scout leaders and almost always university students who have volunteered for the role. They make sure their group attends classes, goes to bed on time, and generally avoids hurting itself (no mean task considering it is composed of hormonal beings in close proximity to Şirince, renowned for its fruit wine!).

Since the number of official staff at the Village is very low, it mostly operates on the commune model. Upon their arrival, students are split up into small groups containing a mixture of high school and university students, with a roughly equal ratio of each. For the next two weeks, these groups will complete the necessary chores to be done in the Village. One day a group will help the cook peel potatoes, the next day it will be on rubbish duty, on the third day responsible for replenishing the various water coolers scattered around the Village, and so forth. Surprisingly enough, far from complaining about this work, many students feel that they have significantly contributed to life at the Village, thus getting a feeling of ownership and community which does not leave them even years later.

\section{Course Structure}

The courses are organized in two-week blocks in order to fit the length of students' stays.

Ordinary high school education in Turkey is geared toward the university entrance examinations. As a result, the emphasis is on memorization, mindless competition, and end result rather than thought processes. The Mathematics Village aims to counteract this by giving high school students a glimpse of what university-level mathematics is.

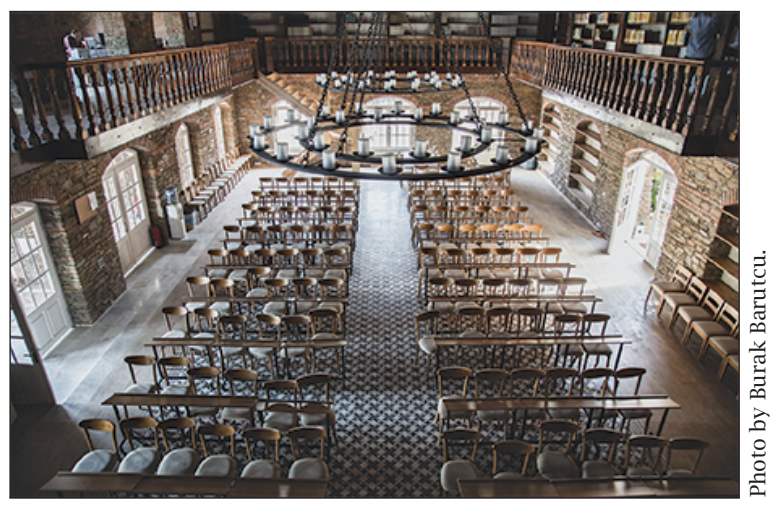

View of the library conference hall from the second floor.

They learn to think for themselves, argue coherently, and spot logical fallacies. Most importantly, they see the process of solving a problem whose solution is not known beforehand. As an example, an exercise that Ali Nesin often does with a group of new students is to determine whether the mathematical group generated by the Turkish alphabet and with all of the students' names as relators gives the trivial group. Students are encouraged to participate, and it often gets difficult to quiet down the shouting out of ideas from every corner of the classroom.

High school students learn about such diverse topics as graph theory, probability, combinatorics, game theory, and basic analysis and algebra. These are supplemented by eclectic exercise sessions where students are introduced to such problems as Hilbert's Hotel and encouraged to construct their own proofs.

An excerpt from a conversation between a student (who attended for the first time at the age of fourteen) and Ali Nesin when they met at a book signing shows the results:

"You came to the Village, didn't you?" Ali asked.

"Yes, four times actually," he said.

"Did it make a difference?"

"A big one."

"How's that?"

"Sir, when I first came I didn't understand anything. Only the last two days I vaguely had the feeling I was getting it. More than the things I understood, I was so happy to have finally understood something that I came back the next year. The first week I understood nothing again, but I understood everything that was being done the second week! On my third visit I missed nothing. On the fourth I was guessing the teacher's next sentence... High school feels boring now."

The university-level teaching is organized around themes if the lecturers' time permits, allowing not only for concentration of research 


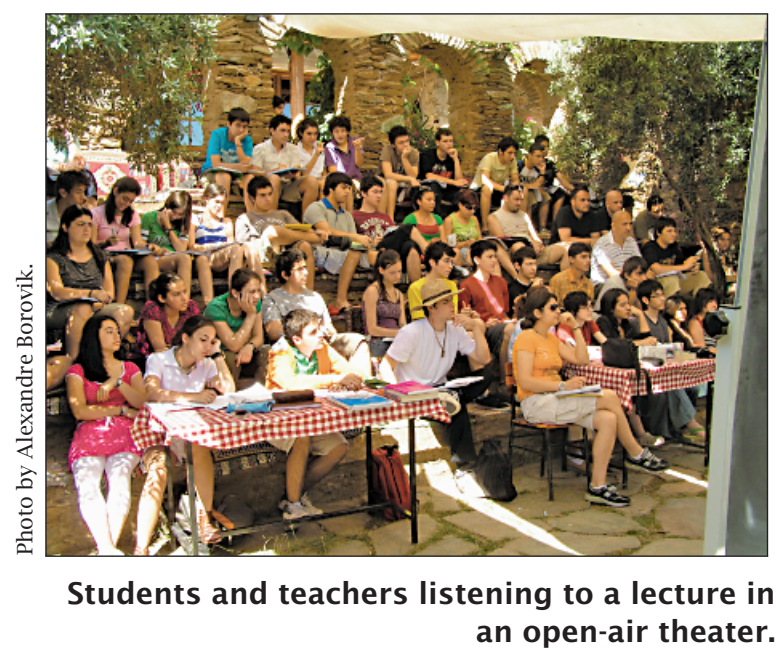

interests but also preparing the ground for cooperation between colleagues in the same or related fields. This year, for example, the second and third weeks saw courses called Reflection Groups, Introduction to Classical Groups, Fundamental Groups, and Three Groups Every Mathematician Has to Know. The range of subjects is too wide to cover here, but university students can learn about anything from Lie algebras to Fourier analysis, from measure theory to representation theory of groups. Some classes can be said to be interdisciplinary between mathematics and philosophy, physics, or computer science, such as Recursion Theory, Gödel's Incompleteness Theorem, or linear programming.

All teaching at the Village is voluntary. In return, lecturers' accommodations and meals are free. Given this, the number of academics who have decided to teach at the Maths Village over the years is truly impressive. Lecturers have come from all over the world, including Alexandre Borovik from Manchester, Edriss Titi from UCI, Max Dickmann from Paris 7, and Ryan O'Donnell from Carnegie Mellon. This list is by no means exhaustive, as listing all contributors here would be impossible.

Apart from the regular teaching, people who do not have enough material for an entire course or simply wish to talk about their own research give seminars in the cool evening breeze at the Aziz Nesin Amphitheatre, organized from 9 to 11 p.m. and attended by whoever wishes to or has enough energy left. These evening talks are very informal-many bring their wine left over from dinner-and are the perfect opportunity to get colleagues' ideas and input to one's research.

\section{Facilities}

The physical structure of the Village today has expanded to contain sixteen dorms (capacity 169), two amphitheatres, two closed and four open-air lecture rooms, one male and one female hammam (Turkish baths), twenty-nine single or double rooms/houses, a fully functional kitchen and cafeteria, a small shop and a magnificent two-story library with a cool breezy terrace in front of it. Even though housing capacity is constantly expanding, many students still stay in tents and therefore pay discounted fees.

The library has an open-plan central area decorated with geometric mosaics. Two gigantic wheel-like chandeliers light a conference hall on the ground floor, seating one hundred fifty. On the second floor balconies overlook the hall; this is where the bookshelves are. Their half-emptiness shows optimism for the future: the library is eager to accept donations of old books and journals. The second floor also holds tables for silent working. It is one of the most peaceful places in the Village, not least because it offers an absolutely unfettered view of the opposing valley. However, the library is far from the only place for working; several isolated areas are available throughout the Village for those who want to escape the excessive friendliness of their colleagues.

Around fifteen paid staff and nearly one hundred volunteers work there every year. The two-week cycles start and end on Sundays, and on that day near-perfect organization is needed to take care of the departure and arrival of hundreds of students without devolving into utter chaos. Ali Nesin sits down with each individual undergraduate student to advise them on which classes they can attend given their background.

No one knows how he manages it, but the cook, Chef Asım, puts out three delicious meals a day and cake at tea time on top of it all.

There are no TVs or broadcast music, although there are occasionally film screenings on the projector in the library. Some evenings students take out their musical instruments-a guitar, occasionally a saz or a kemençe-and give an impromptu concert. Traditional and modern Turkish songs are played, and the listeners join in. To avoid disturbing people who have work to do or need to get up early to attend class, these mini music sessions are often held on Wednesday evenings, as Thursdays are the official day off in the Village.

Each Thursday, a vacation activity is organized. It can be a trip to the nearby Kuşadası, to the further but much more beautiful Kuşadası National Park beach, or a boat tour. Those who wish can organize their own trips, for example, to the historical ruins in Selçuk or the neighboring famous ancient Greek city of Ephesus. Alternatively, one can stay in the Village to catch up on sleep or work in the various secret corners of the Village on the hammocks or swings and couches. 


\section{More Mathematics}

Past Conferences, Workshops, and Research Groups

The main focus of this article has been summer schools, as they are the most active periods of the year for the Nesin Mathematics Village. However, for many years now the Village has also hosted various workshops and conferences throughout the year.

There are various winter schools held during January and February. Some of the workshops which have taken place at the Village are the Algebra and Analysis Workshops in January-February 2014 and October 2013 respectively, the Mathematical Evolution Workshop in September 2013, the Computer Science Workshop in October 2012, and the Workshop on Function Field Arithmetic in June 2014. In May 2014 a summer school Around Valuation Theory was held. The XV Antalya Algebra Days conference, traditionally held in Antalya, as the name indicates, was held in the Mathematics Village in May 2013. Some of the invited speakers were Gregory Cherlin, Martin Ziegler, Ian Leary, and Serge Bouc. The seventeenth edition of this conference will be held in the Village as well, in May 2015.

Recently, the Mathematics Village has started a new initiative whereby research groups of any size can gather in the Mathematics Village for intensive periods of work and collaboration. I personally saw the benefit of this initiative; the day after we arrived, my supervisor and I sat down to work on a problem that had been eluding us for a long time at 9 a.m. after a nice breakfast. Three hours later, we had the basis of a paper-the air of the Mathematics Village is inspiring!

\section{How You Can Use or Contribute to the Mathematics Village}

As described above, the Nesin Mathematics Village is a perfect place to organize a conference or a workshop. The communal feeling of the Village is very likely to leak into any activity taking place there, and the relaxed and intimate surroundings foster communication and collaboration among participants. The same holds for research groups; there are uncountably many corners of the Mathematics Village where a small group can hole up and discuss to their hearts' content without distractions.

Volunteers for teaching are always welcome. Unfortunately, all high school courses must be taught in Turkish, as the students do not necessarily know foreign languages, but any undergraduate or postgraduate course may be taught in English. One of the most common pieces of feedback I have gotten from lecturers at the Mathematics Village is

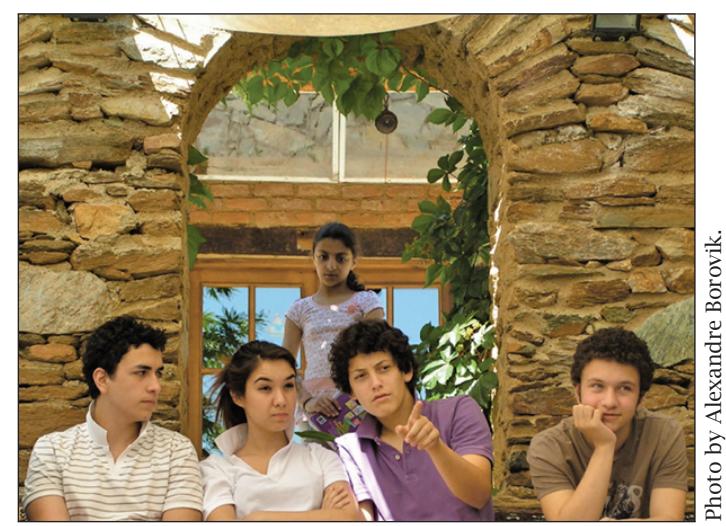

The boy in the purple shirt follows the solution and explains it to a classmate.

how astounded they are at the level of enthusiasm of the students; the sheer hunger for knowledge they have is truly admirable, especially considering that attending these courses is entirely due to personal interest and does not provide any course credits or diploma of any kind.

Teaching and research need not be exclusive. Here is Alexandre Borovik's account of one of his many experiences at the Village:

"For me, the Village is a place of research; I come there to work with my friends and co-authors, Adrien Deloro from Paris and Sükrü Yalçınkaya from Istanbul. We are working on several loosely related projects focused, roughly speaking, on achieving a better understanding of the group $S L_{2}$ at a very detailed, "subatomic" level. To get some taste, see our preprints. The Village is a paradise for work in a small group.

The strange name of the course that I taught last August in the Village is mentioned above: Three groups every mathematician has to know. The groups were the three most famous forms of $S L_{2}: S O_{3}(\mathbb{R}), P G L_{2}(\mathbb{R})$, and $P S L_{2}(\mathbb{C})$. For our projects, I needed to refresh and sharpen my understanding of these groups, and bring it into a usable state; what better way to do so than to give, from first principles, relaxed and free flowing lectures on these groups, and to make them as accessible to listeners as possible? Can you quickly explain-and in the simplest possible way-why the cross-product of vectors in $\mathbb{R}^{3}$ is the Lie algebra of $\mathrm{SO}_{3}(\mathbb{R})$ ? Or Dirac's cup trick? Of course, I gave due attention to geometries of the groups, and paid tributes to glorious names associated with them: Euclid, Lobachevsky, Minkowski.

When you teach to absolute novice learners, you learn, too. Perhaps occasionally I slipped into the entertainment mode and used juicy historical morsels, such, say, as polishing of spherical stone vases in Egypt during the Old Dynasty (or, in mathematical terms, classification of 3-dimensional subalgebras in the Lie algebra of 
AMERICAN MATHEMATICAL SOCIETY

NEED JUST ONE ARTICLE FOR YOUR RESEARCH

\section{Purchase Content}

Now you can buy or rent access to individual AMS journal articles through the Copyright Clearance Center's RightsLink ${ }^{\circledR}$ system.

Look for "Purchase Content" buttons on ams.org journal issue and article pages, and visit ams.org/rightslink for full details.

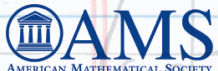
BOOKSTORE

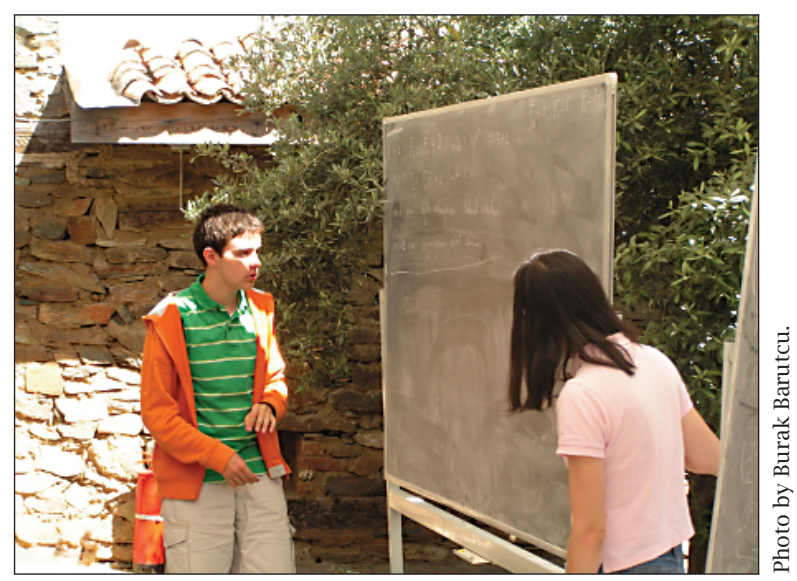

A high school student solves a problem on the blackboard while lecturer Mübe Kanuni looks on.

"sliding vectors", that is, infinitesimal isometries of the 3-dimensional Euclidean space)-but for me it was a way to relax after intensive research sessions.

I do not know any other mathematical establishment in the world where you may find this level of fusion of research and enlightenment."

\section{Future Plans for the Mathematics Village}

Some events are already planned for the upcoming year, apart from the usual summer school: for example, the CIMPA Research School on Leavitt Path Algebras and Graph $C^{*}$-algebras or the 2nd Colloquium on Existentialism.

Due to extensive interest from departments of philosophy, one of the new projects at the Mathematics Village is to build an attached Philosophy Village on the new land purchased. Housing is already being built there, although for now it mostly houses the overflow from the Mathematics Village. Eventually, it may be possible to construct an Arts Village as well, planned as a communal area providing (mostly plastic) artists with studios, to be used as a kind of artist's retreat.

Apart from this, construction at the Mathematics Village itself is still very much in progress. More housing is being built in the hopes that eventually all students will be able to stay in dorms rather than tents.

Ambitious plans are not lacking at the Mathematics Village! Neither are enthusiastic and generous volunteers who do their best to bring them to life and without which the Village could not survive. But more plans, more volunteers, and more input are always welcome, and its residents are always eager to share their pride in the Village with any visitors. ${ }^{1}$

${ }^{1}$ For more information, visit the Village's webpage matematikkoyu.org/eng/. 